MEDICINE

\title{
Ethnicity and attitudes towards life sustaining technology
}

\author{
Leslie J. Blackhall ${ }^{\mathrm{a}}$, Gelya Frank ${ }^{\mathrm{b}}$, Sheila T. Murphy ${ }^{\mathrm{c}}$, Vicki Michel ${ }^{\mathrm{a}}$, \\ Joycelynne M. Palmer ${ }^{\mathrm{d}}$, Stanley P. Azen ${ }^{\mathrm{d}, *}$ \\ ${ }^{a}$ Pacific Center for Health Policy and Ethics and Department of Medicine, University of Southern California School of Medicine, Los \\ Angeles, CA 90033, USA \\ ${ }^{\mathrm{b}}$ Department of Occupational Therapy and Anthropology, University of Southern California, Los Angeles, CA 90033, USA \\ ${ }^{\mathrm{c}}$ Annenberg School for Communication and Department of Psychology, University of Southern California, Los Angeles, CA 90033 , \\ USA \\ ${ }^{\mathrm{d}}$ Department of Preventive Medicine, University of Southern California School of Medicine, 1540 Alcazar St., CHP 218, Los Angeles, \\ CA 90033, USA
}

\begin{abstract}
The ethical and legal implications of decisions to withhold and withdraw life support have been widely debated. Making end-of-life decisions is never easy, and when the cultural background of doctor and patient differ, communication about these issues may become even more difficult. In this study, we examined the attitudes of people aged 65 and older from different ethnic groups toward forgoing life support. To this end, we conducted a survey of 200 respondents from each of four ethnic groups: European-American, African-American, KoreanAmerican and Mexican-American (800 total), followed by in-depth ethnographic interviews with 80 respondents.

European-Americans were the least likely to both accept and want life-support $(p<0.001)$. Mexican-Americans were generally more positive about the use of life-support and were more likely to personally want such treatments $(p<0.001)$. Ethnographic interviews revealed that this was due to their belief that life-support would not be suggested if a case was truly hopeless. Compared to European-Americans, Korean-Americans were very positive regarding life-support $(\mathrm{RR}=6.7, p<0.0001)$; however, they did not want such technology personally $(\mathrm{R} R=1.2$, $p=0.45$ ). Ethnographic interviews revealed that the decision of life support would be made by their family. Compared to European-Americans, African-Americans felt that it was generally acceptable to withhold or withdraw life-support $(\mathrm{RR}=1.6, p=0.06)$, but were the most likely to want to be kept alive on life-support $(\mathrm{RR}=2.1$, $p=0.002$ ). Ethnographic interviews documented a deep distrust towards the health care system and a fear that health care was based on one's ability to pay.

We concluded that (a) ethnicity is strongly related to attitudes toward and personal wishes for the use of life support in the event of coma or terminal illness, and (b) this relationship was complex and in some cases, contradictory. (C) 1999 Elsevier Science Ltd. All rights reserved.
\end{abstract}

Keywords: Survey; Interview; Ethnicity; Ethics; End-of-life decision making

* Corresponding author. Tel.: + 1-323-442-1810; fax: + 1-323-442-2993. 


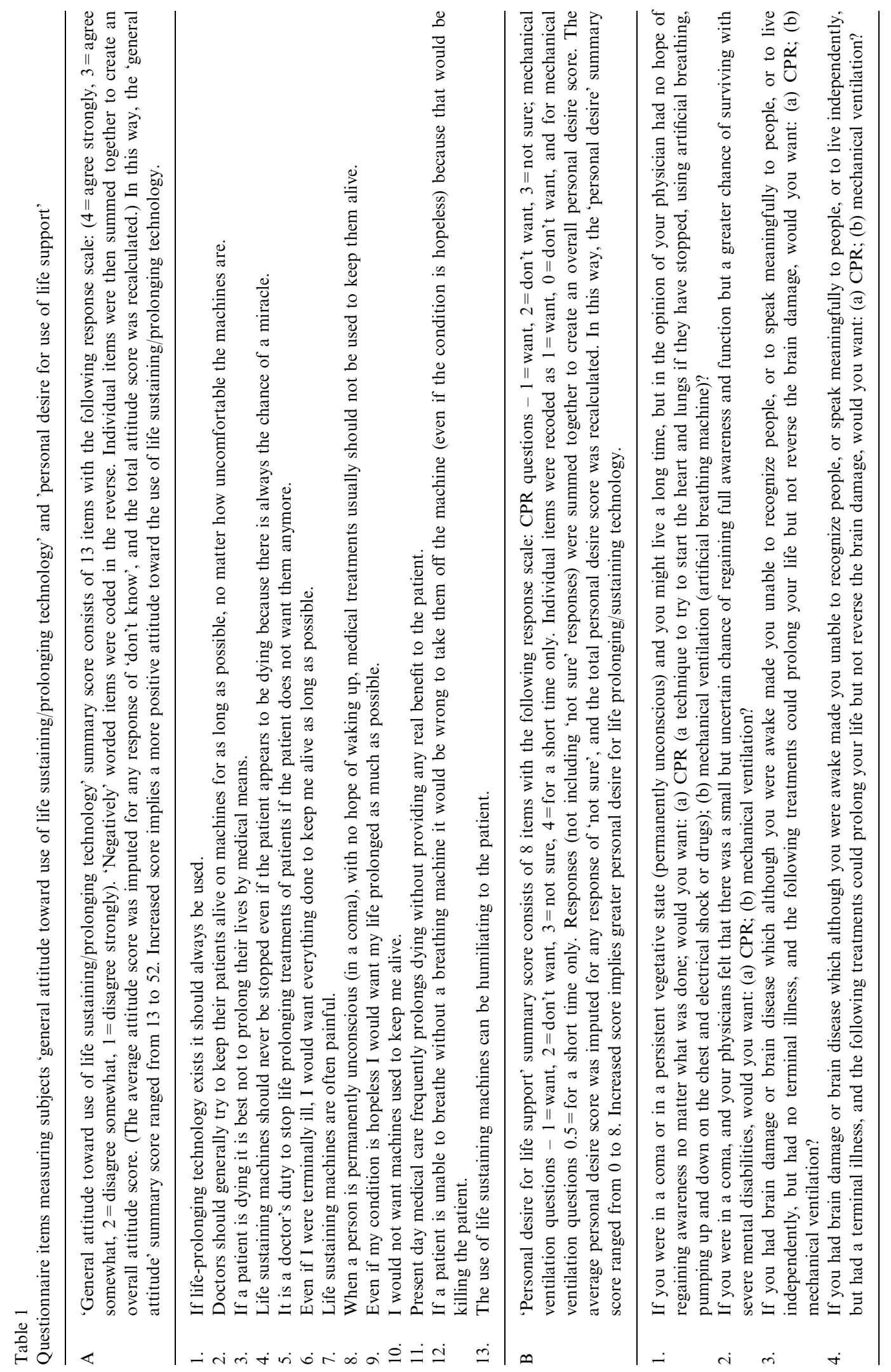




\section{Introduction}

The ethical and legal implications of decisions to withhold and withdraw life support have been widely debated. The consensus in the United States is that it is acceptable to forgo life support under certain circumstances with permission of the patient or a surrogate (American Thoracic Society, 1991; Council on Ethical and Judicial Affairs, 1991). Practice in this regard, however, varies widely from country to country and over time (Asplund and Britton, 1990; Aarons and Beeching, 1991; Nishida and Sakamoto, 1992; Ryan et al., 1993; van Delden et al., 1993; Koch et al., 1994). Making end-of-life decisions is never easy, and when the cultural background of doctor and patient differ, communication about these issues may become even more difficult.

In this study, we examine the attitudes of people aged 65 and older from different ethnic groups toward forgoing life support. Although prior work has documented that beliefs about such topics as truth telling, patient autonomy, euthanasia, advance directives and the use of life support vary widely from one ethnic group to the next, the reasons for and meanings of these differences frequently remain unclear (Holland et al., 1987; Teno et al., 1990; Dalla-Vorgia et al., 1992; Klessig, 1992; Muller and Desmond, 1992; Sugarman et al., 1992; Caralis et al., 1993; Orona et al., 1994; Blackhall et al., 1995; Murphy et al., 1996). In this study we were interested not only in whether KoreanAmerican, Mexican-American, African-American and European-American elders felt it was permissible to withhold life support under certain circumstances but also the underlying reasons why they held these beliefs and the context within which these beliefs took shape. To this end we used a combination of survey questionnaires and in-depth ethnographic interviews in order to better elucidate the sometimes complex belief systems of our respondents.

\section{Methods}

\section{The Ethnicity and Attitudes Study Survey}

For the first phase of the study, a survey was conducted of 800 individuals aged 65 and older residing in Los Angeles County, who identified themselves as belonging to one of the following four ethnic groups: African-American, European-American, KoreanAmerican, and Mexican-American (200 in each group). A stratified quota sampling procedure was employed to ensure that the four ethnic groups did not differ in terms of gender (100 males and 100 females) or age of the research participants (RPs). Additional efforts to avoid bias and details of the study methods have been previously published (Blackhall et al., 1995; Murphy et al., 1996). Participation was voluntary and respondents were given US\$20 in exchange for their time. The study was approved by the University of Southern California Institutional Review Board.

The Ethnicity and Attitudes Toward Advance Care Directives Questionnaire is an instrument based on both previously validated scales as well as scales designed specifically to measure issues relevant to this study. Sections, designed by the Ethnicity and Attitudes research team, underwent testing for internal (construct and content) and external validity. Trained interviewers, of the same ethnic group as the RP, administered the survey in a one-on-one private setting. Mexican-American and Korean-American RPs were interviewed in Spanish and Korean, respectively, using validated versions of the study questionnaire. Following the survey interview, all interviewers completed an informational cover sheet on the RP which rated his/her willingness to participate in a future interview and articulateness.

Table 1 lists the interview questions that were asked in order to ascertain the RP's attitude toward use of life sustaining/prolonging technology ('general attitude'), and their personal desire for use of life support ('personal desire'). The RP's 'general attitude' toward life sustaining/prolonging technology was obtained from 13 items each measured by a four-point response scale. In order to ensure appropriate understanding of questionnaire items and verify continuity of each subject responses, 'general attitude' questions were both worded 'positively' (in favor of life sustaining/prolonging technology) and 'negatively' (opposed to life sustaining/prolonging technology). The 13 individual items were summed together (after recoding negative items) to create the 'general attitude' score, with increased score indicating a more positive attitude toward the use of life sustaining/prolonging technology.

'Personal desire' for life support was established from 8 items Table 1. 'Personal desire' items were designed to obtain the RP's personal desires for life sustaining/prolonging technology in four different hypothetical situations. These scenarios were drawn from a widely used advance directive document (Emanuel and Emanuel, 1989). For the four items related to cardiopulmonary resuscitation (CPR), three response choices were given (want, don't want, and not sure). For the four items related to mechanical ventilation, four response choices were given (want, don't want, not sure, and for a short time only). The items were then summed together to create a preference score, with an increased score indicating greater personal desire for life prolonging/sustaining technology.

'General attitude' towards the use of life sustaining/ 
Table 2

Characteristics related to 'general attitude toward use of life sustaining/prolonging technology' and 'personal desire for life support': univariate analysis. Means with the same letter are not significantly different at the 0.001 level using the Scheffe multiple comparison procedure

\begin{tabular}{|c|c|c|c|c|c|}
\hline \multirow[t]{2}{*}{ Characteristic } & \multirow[t]{2}{*}{$n$} & \multicolumn{2}{|c|}{ Attitude (range 13-52) } & \multicolumn{2}{|c|}{ Desire (range $0-8$ ) } \\
\hline & & mean (S.D.) & $p$-value & mean (S.D.) & $p$-value \\
\hline \multicolumn{6}{|l|}{ Ethnic group } \\
\hline European-American & 200 & $24.5(7.6)^{\mathrm{a}}$ & \multirow[t]{4}{*}{$<0.0001$} & $1.0(1.9)^{\mathrm{a}}$ & \multirow[t]{4}{*}{$<0.001$} \\
\hline African-American & 200 & $28.5(7.4)^{b}$ & & $2.0(2.9)^{\mathrm{b}}$ & \\
\hline Mexican-American & 200 & $30.2(8.2)^{\mathrm{b}}$ & & $1.7(2.8)^{\mathrm{b}, \mathrm{c}}$ & \\
\hline Korean-American & 200 & $33.2(7.6)^{\mathrm{c}}$ & & $1.3(2.7)^{\mathrm{a}, \mathrm{c}}$ & \\
\hline \multicolumn{6}{|l|}{ Gender } \\
\hline Male & 400 & $30.8(8.6)$ & \multirow[t]{2}{*}{$<0.0001$} & $1.9(2.9)$ & \multirow[t]{2}{*}{$<0.0001$} \\
\hline Female & 400 & $27.4(7.6)$ & & $1.1(2.2)$ & \\
\hline \multicolumn{6}{|l|}{ Age (years) } \\
\hline $64-70$ & 235 & $29.1(8.0)$ & \multirow[t]{4}{*}{0.53} & $1.5(2.6)$ & \multirow[t]{4}{*}{0.39} \\
\hline $71-75$ & 216 & $29.7(8.6)$ & & $1.6(2.7)$ & \\
\hline $76-80$ & 205 & $28.6(8.0)$ & & $1.3(2.3)$ & \\
\hline $81+$ & 144 & $28.7(8.7)$ & & $1.7(3.0)$ & \\
\hline \multicolumn{6}{|l|}{ Religion raised } \\
\hline Jewish & 48 & $24.5(7.0)^{\mathrm{a}}$ & \multirow[t]{5}{*}{$<0.0001$} & $1.1(2.1)$ & \multirow[t]{5}{*}{0.26} \\
\hline Prot./Christian & 313 & $27.9(7.9)^{\mathrm{b}}$ & & $1.7(2.7)$ & \\
\hline Catholic & 267 & $29.4(8.5)^{\mathrm{b}, \mathrm{c}}$ & & $1.5(2.6)$ & \\
\hline Other & 80 & $31.3(8.9)^{\mathrm{c}, \mathrm{d}}$ & & $1.3(2.5)$ & \\
\hline Buddhist & 92 & $32.7(7.2)^{\mathrm{d}}$ & & $1.2(2.6)$ & \\
\hline \multicolumn{6}{|l|}{ Religiosity } \\
\hline$\leq 6.7$ (low) & 311 & $27.7(8.2)$ & \multirow[t]{2}{*}{$<0.0001$} & $1.3(2.4)$ & \multirow[t]{2}{*}{0.17} \\
\hline$>6.7$ (high) & 489 & $30.0(8.2)$ & & $1.6(2.7)$ & \\
\hline \multicolumn{6}{|l|}{ Years of schooling } \\
\hline $1-6$ & 198 & $30.4(8.1)$ & \multirow[t]{2}{*}{$<0.01$} & $1.8(3.0)$ & \multirow[t]{2}{*}{0.07} \\
\hline$\geq 7$ & 572 & $28.5(8.4)$ & & $1.4(2.5)$ & \\
\hline \multicolumn{6}{|l|}{ Personal income } \\
\hline$<\$ 10,000$ & 538 & $30.3(8.3)$ & \multirow[t]{2}{*}{$<0.0001$} & $1.6(2.7)$ & 0.24 \\
\hline$\geq \$ 10,000$ & 229 & $26.3(7.5)$ & & $1.3(2.3)$ & \\
\hline Personal experience: illn & & & & & \\
\hline 0 (none) & 164 & $31.3(8.1)$ & $<0.0001$ & $1.5(2.9)$ & 0.76 \\
\hline $1+($ some $)$ & 635 & $28.5(8.3)$ & & $1.5(2.5)$ & \\
\hline Personal experience: wit & care & & & & \\
\hline 0 (none) & 572 & $30.4(8.1)$ & $<0.0001$ & $1.6(2.7)$ & $<0.01$ \\
\hline $1+($ some $)$ & 228 & $25.7(7.9)$ & & $1.1(2.2)$ & \\
\hline Access to health care: st & arriers & & & & \\
\hline$\leq 4.2(\mathrm{few})$ & 492 & $28.9(8.5)$ & 0.51 & $1.3(2.5)$ & $<0.01$ \\
\hline$>4.2$ (many) & 308 & $29.3(8.0)$ & & $1.8(2.8)$ & \\
\hline Insurance & & & & & \\
\hline Government assisted & 473 & $30.9(8.2)$ & $<0.0001$ & $1.6(2.8)$ & 0.43 \\
\hline Private & 308 & $26.2(7.7)$ & & $1.4(2.3)$ & \\
\hline Functional status: Katz & & & & & \\
\hline$\leq 11.6(\mathrm{low})$ & 208 & $28.1(7.7)$ & 0.06 & $1.3(2.3)$ & 0.30 \\
\hline$>11.6$ (high) & 592 & $29.4(8.5)$ & & $1.6(2.7)$ & \\
\hline
\end{tabular}

prolonging technology, and 'personal desire' for use of life support were examined in relation to: (1) demographic factors (including ethnicity, gender, age, religion, religiosity, years of schooling, and personal income); (2) functional status - as measured by the Katz index of activities of daily living (Katz et al.,
1963); (3) acculturation - as measured by the Marin short acculturation scale (Marin et al., 1987); (4) access to health care; and (5) the RP's experience with illness and with withholding and withdrawing care - as measured by subscales developed specifically for this project, described in detail elsewhere (Blackhall et al., 
1995; Murphy et al., 1996). Measures of religiosity derived from four questions regarding membership in a church or temple, and frequency of attendance, and access to care-based on four items from the Edgecombe hypertension study (James et al., 1984) have also been described in previous work from this study (Blackhall et al., 1995; Murphy et al., 1996).

\section{Statistical analyses}

All analyses were conducted at the 0.05 significance level. For each of the dependent variables, analysis of variance and $\chi^{2}$ procedures were used to test for differences across demographic factors, functional status, personal experience with illness and withholding and withdrawing care, and access to health care. Logistic regression analyses were conducted to relate the likelihood of having a positive 'general attitude' toward the use of life sustaining/prolonging technology and also having a 'personal desire' for use of life support (dependent variables, dichotomized at the mean of the distribution) with each of the demographic, functional status, personal experience, and access to health care factors (independent variables) found to be significant in the univariate analyses outlined above.

\section{Ethnographic interviews}

For the second phase of this study, 80 RPs (20 RPs in each ethnic group) were selected for in-depth ethnographic interviews. Participants were selected using standard case sampling; however, at least two cases in each group were selected from the individuals whose responses were atypical in order to get insight into the diversity within groups. Within each group of typical or atypical cases, respondents were further selected for personal experiences with serious illness in self or family (as recorded in survey), articulateness (as reported by survey interviewer), demographic characteristics (socioeconomic status, religion and gender), and willingness to participate in a second interview. Participants were paid US\$25 for their time.

All interviews were conducted by Ph.D.-level anthropologists who were members of the RP's ethnic group and had expertise working in those groups. Interviews were conducted in the participant's language of choice. The qualitative interview guide was structured according to a standard set of sections and domains. Direct questions, conversational probes, and scenarios based on hypothetical cases were used to elicit open-ended responses about experiences and attitudes related to end-of-life care. All interviews were tape recorded, and transcribed verbatim. Spanish and Korean language transcripts were then translated into English. All transcriptions and translations were checked by the interviewer for accuracy.

\section{Data analysis}

All 80 interviews were formatted using the Ethnograph computer program for coding and retrieving data. A uniform set of codes included such domains as truth-telling, attitudes toward forgoing life support, experiences with the health care system and others. Trustworthiness was enhanced by piloting to achieve consensus in the use of codes, consultation among coders, and on-going review of the fit between codes and data. In addition to the coding procedure, all interviews were read and analyzed for emerging themes in discussions among the principal investigators and the anthropologist interviewers.

\section{Results}

\section{Survey data: univariate analysis}

Table 2 presents the relationship of ethnicity, along with other demographic and experiential factors, to the respondent's general attitude and desire toward the use of life sustaining/prolonging technology. There was significant variability in 'general attitude' toward the use of life sustaining/prolonging technology across ethnic groups $(p<0.0001)$. European-Americans had the least positive general attitude toward the use of life sustaining technology, African-Americans and Mexican-Americans had a more positive attitude than European-Americans, and Korean-Americans had the most positive general attitude toward the use of life sustaining technology. Men possessed a significantly more positive general attitude toward the use of life sustaining technology than women $(p<0.0001)$. Buddhists, and those who showed a high level of religiosity had the most positive attitude toward life support $(p<0.0001)$. Lower educational level $(p<0.01)$ and lower income $(p<0.0001)$ were also associated with a more positive general attitude about the use of life support. Personal experience with illness and with withholding medical care were associated with a less positive general attitude $(p<0.0001)$. No significant differences in general attitude were found for age, or access to health care. Functional status was of marginal significance, with people of higher functional status having a more positive general attitude $(p=0.06)$. Those with government assisted insurance had a more positive general attitude toward the use of life support.

Ethnicity was also strongly correlated with personal desires for life support $(p<0.001)$, but in this case the pattern was somewhat different. African-Americans, who tended to have a negative general attitude toward the use of life support, nevertheless were most likely to personally want life prolonging technology. KoreanAmericans who had the most positive general attitude 


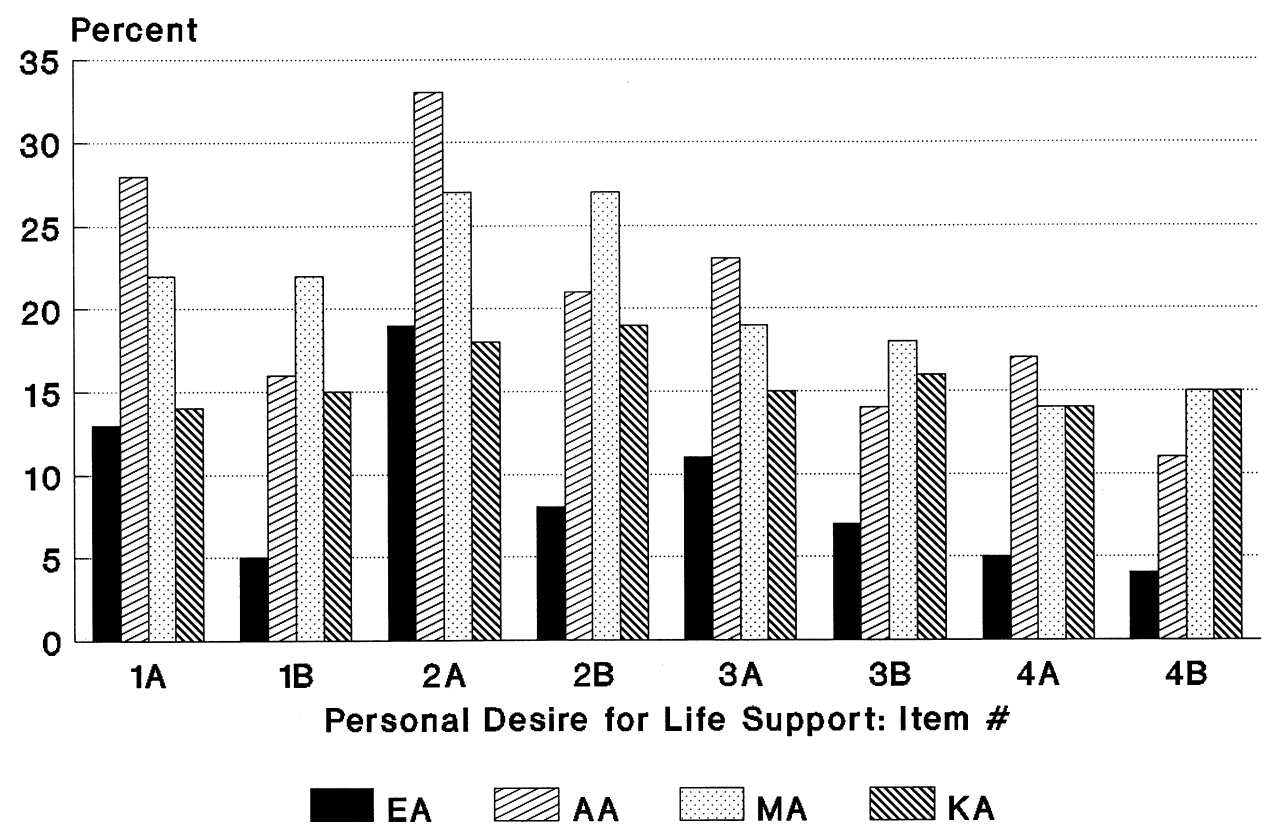

Fig. 1. Percent distribution across ethnic groups of personal desire for life support items: $1=$ in coma with no hope of regaining awareness; $2=$ in coma with small chance of regaining awareness; $3=$ brain damage, no terminal illness; $4=$ brain damage with terminal illness; $\mathrm{A}=\mathrm{CPR} ; \mathrm{B}=$ mechanical ventilation (see Table 1 for complete phrasing of items). EA=European-Americans, $\mathrm{AA}=$ African-Americans, $\mathrm{MA}=$ Mexican-Americans, $\mathrm{KA}=$ Korean-Americans. Significant differences were found across ethnic groups for each item $(p<0.001)$.

about the use of life support, nevertheless had a low personal desire for life support. Mexican-Americans had both a more positive general attitude about the use of life support and were more likely to want such life support for themselves. European-Americans, who had the most negative general attitude about the use of life support, were also the least likely to personally want life prolonging technology. Fig. 1 shows the percentage of each ethnic group who would personally want life support under each of the four scenarios.

Gender, personal experience with withholding care, and access to care were also associated with personal desires for life support $(p<0.01)$. Men, those with no prior experience in decisions to withhold care and those who had many structural barriers to health care were more likely to personally desire life support under the various scenarios. Those with lower educational levels were marginally more likely to personally want life support $(p=0.07)$.

\section{Multivariate analysis}

Factors found to be significantly and independently related to having a positive attitude toward the use of life support were ethnicity, gender, income and personal experience with withholding and withdrawing care (Table 3). Respondents who were more likely to have a positive general attitude toward life prolonging/ sustaining technology were Korean-Americans, male, and had no personal experience with withholding and withdrawing personal care. Factors found to be significantly and independently related to having a personal desire for the use of life support were ethnicity, gender, and access to health care. Respondents who were more likely to possess increased personal desire for the use of life support were African-Americans, male, and had many structural barriers to their accessing health care.

\section{Ethnographic data: Korean-American group}

In this group we focused on a seeming paradox in the questionnaire data - the discrepancy between the positive general attitudes toward life support (where Korean-American RPs were most likely to believe that life support should be continued under all circumstances) and their personal desires for life support (very few Korean-Americans wanted to be kept alive on life support). The responses of RP\#480 proved illuminating. She stated that she personally would not want to be kept alive on life support, but it would not be her decision to make. Rather, it would be her son's decision. His responsibility would be to keep her alive "even one more day" because of hyodo (filial piety), just as it would be her responsibility to do the same 
Table 3

Factors related to 'general attitude toward life prolonging/sustaining technology' and 'personal desire for life support': stepwise logistic regression (mean split)

\begin{tabular}{|c|c|c|c|}
\hline Variable & OR $(95 \% \mathrm{CI})$ & $p$-value & Model $p$-value \\
\hline \multicolumn{4}{|c|}{ Attitude toward life prolonging/sustaining technology } \\
\hline \multicolumn{3}{|c|}{ Ethnic group } & $<0.0001$ \\
\hline European-American & 1.0 & & \\
\hline African-American & $1.6(1.0,2.7)$ & 0.06 & \\
\hline Mexican-American & $3.9(2.4,6.3)$ & $<0.0001$ & \\
\hline Korean-American & $6.7(4.0,11.3)$ & $<0.0001$ & \\
\hline \multicolumn{4}{|l|}{ Gender } \\
\hline Male & 1.0 & & \\
\hline Female & $0.5(0.3,0.7)$ & $<0.0001$ & \\
\hline \multicolumn{4}{|l|}{ Income } \\
\hline$<\$ 10,000$ & 1.0 & & \\
\hline$\geq \$ 10,000$ & $0.4(0.1,0.9)$ & 0.03 & \\
\hline \multicolumn{4}{|c|}{ Personal experience: withholding care } \\
\hline No experience & 1.0 & & \\
\hline Some experience & $0.6(0.4,0.9)$ & 0.01 & \\
\hline \multicolumn{4}{|c|}{ Personal desire for life support } \\
\hline Ethnic group & & & $<0.0001$ \\
\hline European-American & 1.0 & & \\
\hline African-American & $2.1(1.3,3.5)$ & 0.002 & \\
\hline Mexican-American & $1.8(1.1,3.1)$ & 0.03 & \\
\hline Korean-American & $1.2(0.7,2.0)$ & 0.45 & \\
\hline \multicolumn{4}{|l|}{ Gender } \\
\hline Male & 1.0 & & \\
\hline Female & $0.6(0.4,0.7)$ & 0.0002 & \\
\hline \multicolumn{4}{|l|}{ Access to health care } \\
\hline$\leq 4.2($ few $)$ & 1.0 & & \\
\hline$>4.2$ (many) & $1.4(1.0,2.1)$ & 0.05 & \\
\hline
\end{tabular}

for her parent or child. "It may be a contradiction" she told our interviewer "but it's the right thing to do, don't you think?" Similarly, RP\#403 stated that although he would not want life support ("I can clearly say I never want it for myself") he would never make such a decision for one of his children: "I doubt if there is any parent who is able to decide (to remove life support). I don't think parents can ... as long as he (the child) can be alive". RP\#477 reiterated this belief: "If I have such a long term illness, the children will keep me alive ... but I don't want it”. RP\#419 commented that doctors and family members were obliged "to lengthen the life even one second or one minute longer". Thus, the apparent contradiction in the survey data is only a contradiction when viewed through the lens of patient autonomy. For the Korean-American RPs, the family was expected to make all decisions about life support for the patient. As RP\#480 said "I would be the one who was dying so it wouldn't be my decision to make".

\section{Ethnographic data: Mexican-American group}

The Mexican-American group generally favored the use of life support even under circumstances that appeared hopeless. Their personal desires for life support also were relatively greater than those found in the European-American group (see Table 3), although in absolute terms only between $14-27 \%$ wanted such treatments under the different scenarios Fig. 1. In the ethnographic interviews, however, we found that many supported the idea of withdrawing life support under certain circumstances. The dominant theme that emerged in this group was: "If there is no hope, why prolong the suffering?" Many told us of their willingness to forgo life support not only for themselves but also for loved ones, if the doctor felt the condition was hopeless and if the patient was suffering. RP\#605, for example, consented to a do-not-resuscitate order on her father, who had pancreatic cancer, because "he was already dying ... he was in excruciating pain". 
RP\#607 agreed with the doctor to refrain from using life-sustaining technology on her husband, who was severely debilitated after multiple stokes, saying: "Nothing mechanical ... because there would be more suffering". RP\#615, diagnosed with lung cancer, said: "I would ask the doctor for his opinion ... and if he said ... there is nothing more we can do for you ... then I would tell him ... what for? Why cause my family any more suffering?" RP\#726 said: "It would be applied always if ... there were, let's say, a $20 \%$ chance ... but where there isn't [hope] ... what is the idea of prolonging the life and the suffering, and the suffering of the family?"

If these Mexican-American RPs felt comfortable with the idea of forgoing life support, even for a relative, why did they indicate a preference on the survey toward the ongoing use of life support even in apparently hopeless cases? A close reading of the ethnographic data shows that the Mexican-American RPs tend to rely on the doctor's judgment when making decisions about forgoing medical care as in RP\#615, above. This may have influenced the ways they answered the survey questions. For example, in the general attitudes section $78 \%$ of the MexicanAmerican group agreed with the statement "life-sustaining machines should never be stopped even if the patients appears to be dying because there is always the chance of a miracle" (only $29 \%$ of the EuropeanAmerican group agreed with this statement). The Mexican-American RPs may have assumed that the condition in the former only appeared hopeless. Why would a doctor even think of starting life support if the patient were truly hopeless? Follow-up telephone interviews with two of our RPs conducted by the anthropologist supported this reading of the data. We therefore suggest that the many Mexican-Americans expect doctors to suggest or use life support only if there is hope that the patient will survive, and thus would tend to favor continuing such life support if started by the doctor.

\section{Ethnographic data: African-American group}

In the survey most African-American RPs expressed the general attitude that withholding and withdrawing medical care was acceptable under some circumstances. They were more likely than the other groups, however, to personally want to be kept alive by life support. A prominent theme to emerge in the ethnographic interviews was: "Doctors don't know everything". Doctors could not be entirely trusted to know when, and if, to stop life support because their motives might be tainted by economic considerations. As RP\#347 put it: "If [you] ain't got good insurance they ain't gonna let you stay on". RP\#364 related how his sister was removed from life support by physicians before he was ready to have her taken off; he concluded: "Money talks. If you ain't got no money, you're out". RP\#266, whose son died of AIDS, told us he was not put on life support, and said: "They figured out, or assumed that I didn't have any money, so they weren't going to bother". Some of our RPs also expressed the view that doctors don't know everything, only God does. RP\#364 told us that: "The doctor don't know every thing, God might come into it ... He can do more for us than the doctor can". Likewise, RP\#258 said: "I would want to be put on a machine and be here as long as possible ... I believe in a power greater than man ... a miracle or whatever".

Given their doubts about doctors, it is not surprising that many of the African-Americans, discussing the use of life support, said "try it". This was another prominent theme in the ethnographic data. As RP\#399 stated: "Try me on the machine. If it worked, let me stay on". RP\#252 urged: "Hook me up ... save what I've got of life ... (but) when life ceases to be of value then life should be terminated". RP\#384 told us: "Put them on the machine ... exhaust every effort ... until all hope is gone ... Doctors aren't gods and they don't know it all". In saying "try it", most of these respondents were not indicating that life support should continue indefinitely. Instead, they seemed to feel, as RP\#259 put it, that one should "let the patient go on the machine, just for a while anyway". When it becomes clear that the patient's case is hopeless, most were willing to stop, although some would want a prolonged trial, such as RP\#382 who suggested "six months to a year".

\section{Ethnographic data: European-American group}

European-Americans expressed negative general attitudes and personal preferences toward the use of life support. Key themes were "I don't want to live as a vegetable" and "I don't want to be a burden". The term "vegetable", used to describe a permanently comatose state, was a feared outcome of life support and the most frequently cited reason for refusing life sustaining technology. RP\#54 stated: "For a person to ... be a vegetable would be the most horrible thing in the world". RP\#7, whose mother died after multiple strokes, said: "I don't want to live as a vegetable ... Don't do things that simply prolong the illness". Similarly, RP\#108 said: "Vegetable life ... I don't think that is a life to be saved". For the EuropeanAmericans, to be comatose invalidates the patient's status as a social person, which depends, above all, on unimpaired cognitive functioning. As RP\#140 put it: "[I don't $]$ see what the purpose of life is if you're not mentally alive". Furthermore, comatose people are dependent, unable to exert any control over their own fate, and are burdensome to their families. RP\#8 said: 
"I happen to be a person who wants to control my destiny ... I wouldn't want to be dependent". RP\#12 (who told us that he considered Jack Kevorkian a 'saint') told us: "If I would go into any kind of coma, that would last anything more than $24 \mathrm{~h}$, I would say, hey, that's about it ... because I know the burden it sets on other people's head". Similarly RP\#152 said: "I don't want to become a vegetable and be a burden on people".

\section{Discussion}

In this study we found that ethnicity is strongly related to attitudes toward and personal wishes for the use of life support in the event of coma or terminal illness. The relationship between ethnicity, general attitudes and personal desires however, was complex and in some cases, apparently contradictory. For example, although Korean-Americans respondents were the group most likely to express the opinion that life-support should always be used, they usually did not want to have such treatments for themselves. The ethnographic data illuminated this seeming paradox. These Korean-American elders did not believe that their personal desires for life support were relevant to treatment decisions. Such decisions are the responsibility of the family, and the family is strongly obligated by hyodo (filial piety) to prolong the life of a relative as long as possible. Although this attitude appears to violate one of the most deeply held tenets of end-of-life decisionmaking in this country, that is respect for patient autonomy, the Korean-Americans we interviewed seemed quite clear that the "right thing to do" was to honor the wishes of their family, rather than their own preferences. This is consistent with other published analyses from this same data set, which showed our Korean-American respondents to have a strong preference for family-centered styles of decision-making (Blackhall et al., 1995; Murphy et al., 1996).

In direct contrast to the Korean-American group, the African-American group tended to express the general view that it was acceptable to withhold or withdraw care under some circumstances, but were most likely to personally want to be kept alive on life support. Many in this group did not trust doctors; they felt that economic motives were often behind treatment decisions. Some also felt that doctors could not have access to the kind of information necessary to make decisions about the withdrawal of life support, that only God had this kind of knowledge. For these reasons, many were inclined to at least try life support. The experience of African-Americans with the health care system in this country, which includes segregated hospitals, the Tuskegee syphilis study, and a legacy of poor access to and racial discrimination in health care
(Reynolds, 1997) are reasons why many in this group do not take physician's pronouncement at face value, and are therefore inclined to at least try life support.

The European-Americans, as a group, were the most likely to believe that it was acceptable to withhold or withdraw life-support and the least likely to personally want life support under a variety of scenarios. This is consistent with prior research which shows high levels of support for withholding medical care in this group (Cohen-Mansfield et al., 1991; Emanuel et al., 1991; Koch et al., 1994). Fear of being a "vegetable" and of being a burden on loved ones were the reasons cited by many of our subjects for forgoing life support.

Finally, the Mexican-American group had both more generally positive attitude about the use of life support and were more likely to personally want such treatments than did the European-American group. Ethnographic interviews, however, showed them to be more open to the idea of forgoing life support than the survey data would suggest, provided the doctor felt the patient's condition to be hopeless.

One further finding of this study is that attitudes about topics such as these are complex and not easily captured by survey data alone. The ethnographic data did more than merely expand upon the findings of the survey. As illustrated above, it was indispensable in making sense of seeming contradictions in the survey results of the Korean-American and African-American respondents. At times it forced us to revise our understanding of survey data, as in the case of the MexicanAmerican group. We suggest that studies looking at end-of-life decisions should include a qualitative component to help clarify and prevent misunderstanding of data collected in other ways.

Interestingly, gender was also associated with both general attitudes about and personal desires for life support. Across ethnic groups, women were less likely to view the use of life support favorably and less likely to personally want life support than men. Women's disproportionate status as caregivers for sick relatives (documented in our ethnographic interviews) may influence their attitudes toward the use of aggressive life prolonging measures. Clearly, this is a topic that deserves further study.

What concrete recommendations can we make based on these data? First, we suggest that patients be offered the option of making end-of-life decisions for themselves or delegating that responsibility to a family member or members. Second, we believe that it may not be helpful for physicians to view their role in medical decision-making as simply one of objectively offering options without giving an opinion. To a MexicanAmerican patient or family member the question "Should we do CPR?" may be interpreted as meaning that the physician is recommending the use of CPR, when in fact the opposite is likely to be true (Haffner, 
1992). To a traditional Korean-American family this same question may allow only one answer ("yes") which would be consistent with hyodo, even if both patient and family would prefer that the patient not suffer needless at the time of death. By offering an opinion the physician clarifies the context within which he or she is discussing end-of life care, and accepts some responsibility for a decision that might otherwise be almost impossible for the family to make. Finally, decreasing the distrust many African-Americans feel for the health care system will require more than improving communication between doctors and patients. It will require improving access to care and decreasing the institutionalized racism that is still prevalent in our health care institutions.

There are several possible limitations to the generalizability of these data. Our data involves respondents aged 65 and older; younger people may differ in their views. We used a quota sampling technique rather than a true random sample in order to prevent skewing our population toward younger female respondents. Although we attempted to minimize selection bias by sampling from 31 different sites, all segments of these groups may not be represented. Finally, our study was conducted in urban southern California, attitudes may differ in other geographic locations.

It is not the purpose of this work to provide stereotyped descriptions of the attitudes of one group or another. Rather, we wish to point out the variety and complexity of attitudes that are present in a diverse patient population. Furthermore, the focus of the present research is on differences between ethnic groups, there is an enormous amount of within group variability as well. Patients have different life experiences; experiences that are molded by a great many factors such as ethnicity but also socioeconomic status, gender and access to care. A one size fits all approach to medical decision-making is likely in fact to fit relatively few. Understanding this might save us from communications problems and misguided public policy decisions which fail to address the concerns of a large segment of our increasingly multicultural society.

\section{Acknowledgements}

Funding for this project was provided by the Agency for Health Care Policy and Research, R01HS07001.

\section{References}

Aarons, E., Beeching, N., 1991. Survey of "do not resuscitate" orders in a district general hospital. British Medical Journal 303, 1504-1506.
American Thoracic Society, 1991. Withholding and withdrawing life-sustaining. Annals of Internal Medicine 115, 478484.

Asplund, K., Britton, M., 1990. Do-not-resuscitate orders in Swedish medical wards. Journal of Internal Medicine 228, 139-145.

Blackhall, L., Murphy, S., Frank, G., Michel, V., Azen, S., 1995. Ethnicity and attitudes toward patient autonomy. Journal of the American Medical Association 274, 820825.

Caralis, P.V., Davis, B., Wright, K., Marcial, E., 1993. The influence of ethnicity and race on attitudes toward advance directive, life prolonging treatments and euthanasia. Journal of Clinical Ethics 4, 155-165.

Cohen-Mansfield, J., Rabinovich, B., Lipson, S., Fein, A., Gerber, B., Weisman, S., Pawlson, L., 1991. The decision to execute a durable power of attorney for health care and preferences regarding the utilization of life-sustaining treatments in nursing home residents. Archives of Internal Medicine 151, 289-294.

Council on Ethical and Judicial Affairs, American Medical Association, 1991. Guidelines for the appropriate use of do-not-resuscitate orders. Journal of the American Medical Association 265, 1868-1871.

Dalla-Vorgia, P., Katsouyanni, K., Garanis, T.N., Touloumi, G., Drogari, P., Koutselinis, A., 1992. Attitudes of a Mediterranean population to the truth-telling issue. Journal of Medical Ethics 18, 67-74.

Emanuel, L., Emanuel, E., 1989. The medical directive - a new comprehensive advance care document. Journal of the American Medical Association 26, 3288-3293.

Emanuel, L., Barry, M.J., Stoeckle, J.D., et al., 1991. Advance directives for medical care - a case for greater use. New England Journal of Medicine 324, 889-895.

Haffner, L., 1992. Translation is not enough-interpreting in a medical setting. Western Journal of Medicine 157, 255259.

Holland, J.C., Geary, N., Marchini, A., Tross, S., 1987. An international survey of physician attitudes and practice in regard to revealing the diagnosis of cancer. Cancer Investigations 5, 151-154.

James, S.A., Wagner, E.H., Strogatz, D.S., et al., 1984. The Edgecombe high blood pressure control program II: Barriers to the use of medical care among hypertensives. American Journal of Public Health 74, 468-472.

Katz, S., Ford, A.B., Moskowitz, R.W., Jackson, B.A., Jaffee, M.W., 1963. Studies of illness in the aged: the index of ADL, a standardized measure of biological and psychosocial function. Journal of the American Medical Association 184, 914-919.

Klessig, J., 1992. The effect of values and culture on life support decisions. Western Journal of Medicine 157, 316-322.

Koch, K., Rodeeffer, H., Wears, R., 1994. Changing patterns of terminal care management in an intensive care unit. Critical Care Medicine 22, 233-243.

Marin, G., Sabogal, F., Marin, B.V., Otero-Sabogal, R., Perez-Stable, E., 1987. Development of a short acculturation scale for Hispanics. Hispanic Journal of Behavioral Science 9, 183-205.

Muller, J.H., Desmond, B., 1992. Ethical dilemmas in a cross- 
cultural context: a Chinese example. Western Journal of Medicine 157, 323-327.

Murphy, S., Palmer, J., Azen, S., Frank, G., Michel, V., Blackhall, L., 1996. Ethnicity and advance care directives. Journal of Law and Medical Ethics 24, 108-117.

Nishida, H., Sakamoto, S., 1992. Ethical problems in neonatal intensive care-medical decision-making in the neonate with poor prognosis. Early Human Development 29, 403-406.

Orona, C.J., Koenig, B.A., Davis, A.J., 1994. Cultural aspects of nondisclosure. Cambridge Quarterly of Health Ethics 3, 338-346.

Reynolds, P., 1997. Hospitals and civil rights, 1945-1963: the case of Simkins v Moses, H. Cone Memorial Hospital. Annals of Internal Medicine 126, 898-906.
Ryan, C., Byrne, P., Kuhn, S., Tybkan, J., 1993. No resuscitation and withdrawal of therapy in a neonatal intensive care unit in Canada. Journal of Pediatrics $123,534-538$.

Sugarman, J., Weinberger, M., Samsa, G., 1992. Factors associated with veteran's decisions about living wills. Archives of Intenral Medicine 152, 343-347.

Teno, J., Fleishman, J., Brock, D., Mor, V., 1990. The use of formal prior directives among patients with HIV related diseases. Journal of General Internal Medicine $5,490-494$.

van Delden, J., van der Maas, P., Pijenenborg, L., Looman, C., 1993. Deciding not to resuscitate in Dutch hospitals. Journal of Medical Ethics 19, 200-205. 